\title{
Correlates of Insufficient Physical Activity among Junior High School Students: A Cross-Sectional Study in Xi'an, China
}

\author{
Xiaoqin Wang ${ }^{1, *}$, Zhaozhao Hui ${ }^{1}$, Paul D. Terry ${ }^{2}$, Mei Ma ${ }^{1}$, Li Cheng ${ }^{3}$, Fu Deng ${ }^{4}$, Wei Gu ${ }^{1}$ and \\ Bin Zhang ${ }^{1}$ \\ 1 School of Medicine, Xi'an Jiaotong University, Xi'an 710061, Shaanxi Province, China; \\ huizhaozhao93@163.com (Z.H.); wysun201314195@163.com (M.M.); 232guwei@mail.xjtu.edu.cn (W.G.); \\ zhbin@mail.xjtu.edu.cn (B.Z.) \\ 2 Department of Medicine, University of Tennessee Medical Center, Knoxville, TN 37996, USA; \\ pdterry@utk.edu \\ 3 Faculty of Medicine, The Chinese University of Hong Kong, Shatin 999077, Hong Kong, China; \\ lilycheng@link.cuhk.edu.hk \\ 4 Xi'an Tie Yi High School, Xi'an 710000, Shaanxi Province, China; dengfu01@126.com \\ * Correspondence: wangxiaoqin@mail.xjtu.edu.cn; Tel.: +86-029-8265-7015
}

Academic Editor: Paul B. Tchounwou

Received: 22 January 2016; Accepted: 28 March 2016; Published: 1 April 2016

\begin{abstract}
Background: Physical activity plays an important role in individual health at all stages of life. However, evidence is lacking regarding the level of moderate to vigorous physical activity (MVPA) and the related factors to insufficient physical activity (IPA). Methods: A sample of 1060 students aged 12-15 years from nine public junior high schools in China were invited to participate in this study. Physical activity was assessed by a modified version of the International Physical Activity Questionnaire. Logistic regression was used to assess the factors associated with IPA. Results: $30.1 \%$ boys and $43.0 \%$ girls in our sample did not engage in sufficient physical activity. Obesity (OR $=2.2$, 95\% CI: 1.5-2.9) and high socioeconomic status (SES) (OR $=2.4,95 \%$ CI: $1.3-4.8$ ) were positively associated with IPA, whereas male sex (OR $=0.7,95 \%$ CI: $0.5-0.9)$, underweight status (OR $=0.5$, $95 \%$ CI: 0.3-0.7), and high family support level for physical activity (OR $=0.7,95 \%$ CI: $0.6-0.9)$ showed inverse associations. Age was not associated with IPA. Conclusions: IPA appears to be a considerable problem in this sample of Chinese youth. Effective interventions to increase physical activity are needed and may include improving family support level for physical activity, especially for girls, the obese and those with high SES.
\end{abstract}

Keywords: MVPA; adolescent; obesity; socioeconomic status (SES); family support

\section{Introduction}

The World Health Organization (WHO) recommends that children and adolescents aged 5-17 years old should accumulate at least 60 minutes of moderate to vigorous physical activity (MVPA) daily [1]. Physical activity below this level is considered insufficient. A recent systemic review [2] showed that the worldwide prevalence of insufficient physical activity (IPA) varied from $18.7 \%$ to $90.6 \%$, with a median of $79.7 \%$. The U.S. National Survey of Children's Health found that only $28 \%$ of U.S. children aged 6-17 participated in daily vigorous physical activity in 2011-2012 [3]. Decelis et al. found that only $39 \%$ of boys and 10\% of girls met the recommendation of one hour of MVPA in Malta [4]. In Taiwan, it was found that $40.9 \%$ of the adolescent girls and $24.0 \%$ of the adolescent boys did not achieve the WHO recommendations for physical activity [5]. A cross-sectional study in Beijing showed that $30.7 \%-61.3 \%$ of middle school students did not meet the current 
physical activity recommendations, and about half of the students spent excessive time engaging in sedentary behaviors [6]. In these studies, it is possible that measurement error led to underestimates or overestimates of physical activity to varying degrees. Nonetheless, given the consistency of findings across countries, there appears to be a global pandemic of IPA.

IPA has a major influence on the prevalence of chronic and non-communicable diseases such as cardiovascular disease, obesity, diabetes, hypertension, and cancer [7-9]. For adolescents, IPA has also been shown to have deleterious effects on body weight and body composition [10], which has social and psychological implications [11,12]. Indeed, IPA has been linked with increased risk of mental health problems [11], whereas it has been noted that adequate physical activity may reduce symptoms of depression [12]. In addition, a study based on 2225 students in Shanghai suggested that physical activity was associated with higher scholastic performance [13]. Although there are many possible reasons for this latter association, research has demonstrated improvements in cognitive performance in individuals who were physically active during childhood and adolescence [14].

In the past decade, epidemiological studies have examined factors associated with IPA, including gender [5,6], age $[15,16]$, social support for physical activity $[17,18]$, body weight [19], and socioeconomic status (SES) [20]. Parents may often exert considerable influence on the physical activity-related behaviors of youth, with either tangible or intangible support. For instance, parents provide transportation to places where the children can engage in a variety of physical activities, purchase equipment, play with their children, encourage the adolescents to participate in MVPA, and talk about the benefits of physical activity [21,22]. However, few studies have addressed these factors among adolescents in China, which is the most populous country in the world. Therefore, we examined the levels of MVPA among junior high school students in $\mathrm{Xi}^{\prime}$ an, a city in Northwest China, and explored several factors that may be associated with IPA.

\section{Materials and Methods}

\subsection{Ethics Statement}

The study was approved by the Biomedical Ethics Committee of the Department of Medicine Xi'an Jiaotong University (Project identification code: 2014-596). Prior to data collection, all students and their parents had received informed consents of the present study and were assured that they would participate in this study anonymously. Participants were also informed that they could refuse to participate or to answer any questions and could withdraw at any time.

\subsection{Study Sample}

We randomly selected 9 junior high schools from the 240 schools in Xi'an using a random number table. Then, three classes of different grades per school were selected through drawing lots. All students in the chosen classes (1105 students) were invited to participate in this study, but 45 individuals refused to participate. Consequently, 1060 students aged 12 to 15 years participated in this study. And 28 subjects were excluded due to missing data, leaving 1032 students for analysis.

\subsection{Measurement of Demographic Characteristics}

Demographic information included the students' sex, age, home address, SES, weight, and height. The weight and height of each participant were measured twice by study personnel. A third height and/or weight measurement was taken in the rare event that the first two measurements were not in agreement. Body mass index (BMI) was derived from weight and height $\left(\mathrm{kg} / \mathrm{m}^{2}\right)$, and thereafter BMI z-scores were calculated based on growth reference algorithms developed by the WHO for children and youth [23]. The students were grouped into the following BMI status: underweight (BMI $<15$ th percentile), average weight (BMI 15th to 85th percentile), overweight (BMI 85th to 95th percentile), and obese (BMI $>95$ th percentile). SES was assessed by family annual income, 
which was reported by parents of the adolescents. Participants were grouped into three SES: low, median, and high ( $<120,000 \mathrm{RMB}, 120,000$ to 300,000 , and $>300,000 \mathrm{RMB}$, respectively).

\subsection{Family Support Assessment}

We used Lee's family support for physical activity scale (6 items) to measure family support level in the present study [24]. A lower score indicates lower family support for physical activity. We classified the family support distribution according to the percentile scores, dividing the subjects into two groups: high (above the 50th) and low (below the 50th). In the present study, the Cronbach's alpha was 0.80 and the test-retest reliability was $0.83(n=50)$, consistent with estimates from a previous study [24].

\subsection{Physical Activity Assessment}

Physical activity was assessed using the Physical Activity Questionnaire for Middle School Students (PAQMSS), which we modified from the International Physical Activity Questionnaire [25] to specifically assess the physical activity of Chinese middle school students. The PAQMSS was revised according to the results from a qualitative survey $(n=18)$. The reliability and criterion validity of the revised questionnaire was assessed using ActiGraph GT3X triaxial accelerometers that were worn on the right hip of the participants. The activities were classified into three groups: light, moderate, and vigorous (2-3.9 MET, 4-5.9 MET, more than 6 MET) according to the intensity of energy consumption, which was recorded by the accelerometers automatically. The correlation coefficients of validity ranged from 0.584 (long jump) to 0.684 (walking) and the Cronbach's alpha was $0.731(n=50)$. Participants completed the PAQMSS in the classroom in the presence of trained graduate students, who helped the students with any questions or concerns regarding the questionnaire (e.g., whether they should convert the unit "hours" into "minutes" or not.). The PAQMSS included four domains (types, frequency, duration, and intensity of physical activity), and 25 specific physical activities including walking, running, biking, skipping, kicking shuttlecock, swimming, dancing, basketball and other physical activities. Participants were asked the frequency and duration for each activity during last week. The intensity of physical activities was assessed as "none", "a little", "quite a bit" and "very much", which describe the increase in breath and heartbeat after each activity. The categories "quite a bit" and "very much" were considered moderate and vigorous physical activity, respectively. The total time of MVPA was calculated by summing the self-reported frequency and duration for the specific physical activities. IPA was defined as engaging in less than $300 \mathrm{~min}$ per week of moderate to vigorous physical activity [5,15].

\subsection{Data Management and Statistical Analysis}

Data management and statistical analysis were performed using Epidata (version 3.1) (The Epidata Association, Odense, Denmark) and SPSS (Statistical Product and Service Solutions) for Windows (version 21.0) (IBM, Armonk, NY, USA). Results were presented as numbers and percentage for categorical data and were expressed as mean and standard deviation for continuous data. T-tests, analysis of variance and chi-squared tests were performed to analyze differences in demographic data and other study variables. A logistic regression model was used to determine the independent factors related to IPA, with the adjustment of predictive variables including age [15], gender [5,6], BMI status [9], family support for physical activity [17,18], and SES [26]. Age, gender and family support for physical activity were used as dichotomized variables, whereas BMI status and SES were coded as ordered categorical variables in logistic regression models. Statistical significance was set at $p<0.05$, and all tests were two-sided. 


\section{Results}

\subsection{Demographic Characteristics of Participants}

The mean ages of boys and girls in our study population were $13.8 \pm 0.8$ and $13.9 \pm 0.9$ years, respectively (Table 1). Compared with girls, more boys were overweight $(12.8 \%$ vs. $7.1 \%, p<0.001)$ and obese $(28.2 \%$ vs. $14.8 \%, p<0.001)$. Overall, $30.1 \%$ of boys and $43.0 \%$ of girls did not meet the recommendation of 300 minutes MVPA per week. In contrast, boys (58.1\%) showed a high level of family support for physical activity than girls $(37.9 \% ; p=0.002)$. Boys $(40.1 \%)$ showed a slightly higher prevalence of low SES than girls $(35.9 \% ; p<0.001)$.

Table 1. Distribution of demographic data among junior high school students $(n=1032)$.

\begin{tabular}{|c|c|c|c|c|c|}
\hline \multirow[t]{2}{*}{ Variables } & Boys $(n=539)$ & Girls $(n=493)$ & \multirow[t]{2}{*}{$t$} & \multirow[t]{2}{*}{$X^{2}$} & \multirow[t]{2}{*}{$p$} \\
\hline & $n(\%)$ & $n(\%)$ & & & \\
\hline Age (Mean \pm SD) & $13.8 \pm 0.8$ & $13.9 \pm 0.9$ & -1.880 & & 0.078 \\
\hline BMI status & & & & 45.596 & $<0.001$ \\
\hline Average weight & $248(46.0)$ & $281(57.0)$ & & & \\
\hline Underweight & $70(13.0)$ & $104(21.1)$ & & & \\
\hline Overweight & $69(12.8)$ & $35(7.1)$ & & & \\
\hline Obese & $152(28.2)$ & $73(14.8)$ & & & \\
\hline Socialeconomic status & & & & 27.389 & $<0.001$ \\
\hline Low & $216(40.1)$ & 177 (35.9) & & & \\
\hline Medium & $259(48.1)$ & $296(60.0)$ & & & \\
\hline High & $64(11.8)$ & $20(4.1)$ & & & \\
\hline Family support level & & & & 10.053 & 0.002 \\
\hline Low & $226(41.9)$ & $306(62.1)$ & & & \\
\hline High & $313(58.1)$ & $187(37.9)$ & & & \\
\hline Time to walk from home to recreation/parks & & & & 3.835 & 0.147 \\
\hline$<10 \mathrm{~min}$ & $153(28.4)$ & $120(24.3)$ & & & \\
\hline 10-20 min & $228(42.3)$ & $203(41.2)$ & & & \\
\hline$>30 \mathrm{~min}$ & $158(29.3)$ & $170(34.5)$ & & & \\
\hline Time spent outside & & & & 0.157 & 0.925 \\
\hline$<1 \mathrm{~h}$ & $301(37.3)$ & $182(36.9)$ & & & \\
\hline $1-2 \mathrm{~h}$ & $299(55.5)$ & $278(56.4)$ & & & \\
\hline$>2 \mathrm{~h}$ & $39(7.2)$ & $33(6.7)$ & & & \\
\hline \multicolumn{6}{|l|}{ Screen time } \\
\hline Week days & & & & 0.026 & 0.873 \\
\hline$\leqslant 2 \mathrm{~h}$ & $384(71.2)$ & $349(70.8)$ & & & \\
\hline$>2 \mathrm{~h}$ & $155(28.8)$ & $144(29.2)$ & & & \\
\hline Weekend days & & & & 0.004 & 0.947 \\
\hline$\leqslant 2 \mathrm{~h}$ & 199 (36.9) & $183(37.1)$ & & & \\
\hline$>2 \mathrm{~h}$ & $340(63.1)$ & $310(62.9)$ & & & \\
\hline Insufficient physical activity & & & & 18.667 & $<0.001$ \\
\hline Yes & $162(30.1)$ & $212(43.0)$ & & & \\
\hline No & $377(69.9)$ & $281(57.0)$ & & & \\
\hline
\end{tabular}

Notes: SD: standard deviation; BMI: body mass index.

\subsection{Description of Physical Activity}

Girls ( $515 \pm 497 \mathrm{~min} /$ week) were less active than boys ( $828 \pm 701 \mathrm{~min} /$ week) and had a higher percentage of IPA (43.0\% vs. 30.1\%). Compared with underweight subjects, obese adolescents were more likely to report IPA (17.8\% vs. 52.4\%). Students from families with high SES (53.6\%) also showed a higher prevalence of IPA compared with those from families with low (38.4\%) and medium SES $(32.1 \%)$. Students who reported high family support for physical activity were less likely to report IPA $(29.0 \%)$ than those reporting low family support $(43.0 \%)$. On weekdays, there was no significant association between screen time and IPA. In contrast, there was an inverse association between screen time and MVPA on weekends (Table 2). 
Table 2. Comparison of the amounts of moderate to vigorous physical activity (MVPA) and insufficient physical activity (IPA) $(n=1032)$.

\begin{tabular}{|c|c|c|c|c|c|c|c|}
\hline \multirow{2}{*}{ Variables } & \multicolumn{3}{|c|}{ MVPA } & \multirow[b]{2}{*}{$t$} & \multirow[b]{2}{*}{$F$} & \multirow{2}{*}{$\begin{array}{c}\text { IPA } n / \text { Total } \\
(\%)\end{array}$} & \multirow[b]{2}{*}{$X^{2}$} \\
\hline & (Min/Week) & Median & $\begin{array}{l}\text { 25th-75th } \\
\text { Percentile }\end{array}$ & & & & \\
\hline Gender & & & & $6.699 * *$ & & & $18.677^{* *}$ \\
\hline Boys & $828 \pm 701$ & 610 & $290-1215$ & & & $162 / 539(30.1)$ & \\
\hline Girls & $515 \pm 497$ & 390 & $205-775$ & & & $212 / 493(43.0)$ & \\
\hline BMI status & & & & & 7.620 & & $51.455 * *$ \\
\hline Average weight & $736 \pm 603$ & 470 & $230-860$ & & & $190 / 529(35.9)$ & \\
\hline Underweight & $655 \pm 661$ & 591 & $327-1088$ & & & $31 / 174(17.8)$ & \\
\hline Overweight & $812 \pm 694$ & 566 & $260-1005$ & & & $35 / 104(33.7)$ & \\
\hline Obese & $547 \pm 514$ & 619 & $302-1297$ & & & $118 / 225(52.4)$ & \\
\hline SES & & & & & 9.138 & & $15.902 * *$ \\
\hline Low & $724 \pm 568$ & 655 & 317-992 & & & $151 / 393(38.4)$ & \\
\hline Medium & $685 \pm 59$ & 502 & $278-1037$ & & & $178 / 555(32.1)$ & \\
\hline High & $520 \pm 607$ & 413 & $215-915$ & & & $45 / 84(53.6)$ & \\
\hline Family support level & & & & $-4.54^{* *}$ & & & $22.01 * *$ \\
\hline Low & $616 \pm 602$ & 391 & $155-703$ & & & $229 / 532(43.0)$ & \\
\hline High & $855 \pm 747$ & 702 & $382-1312$ & & & $145 / 500(29.0)$ & \\
\hline Time to walk from home to recreation & & & & & 13.366 & & 0.092 \\
\hline$<10 \mathrm{~min}$ & $751 \pm 596$ & 671 & $321-987$ & & & $101 / 273(37.0)$ & \\
\hline $10-30 \mathrm{~min}$ & $699 \pm 604$ & 515 & $298-1015$ & & & $155 / 431(36.0)$ & \\
\hline$>30 \mathrm{~min}$ & $642 \pm 621$ & 443 & $233-998$ & & & $118 / 328(36.0)$ & \\
\hline Time spent outside & & & & & $\underset{* *}{52.229}$ & & 2.102 \\
\hline$<1 \mathrm{~h}$ & $445 \pm 569$ & 492 & $229-722$ & & & $128 / 383(26.5)$ & \\
\hline $1-2 \mathrm{~h}$ & $731 \pm 711$ & 687 & $362-969$ & & & $219 / 577(38.0)$ & \\
\hline$>2 \mathrm{~h}$ & $829 \pm 738$ & 722 & $325-947$ & & & $27 / 72(37.5)$ & \\
\hline \multicolumn{8}{|l|}{ Screen time } \\
\hline Week days & & & & -1.666 & & & 0.585 \\
\hline$\leqslant 2 \mathrm{~h}$ & $674 \pm 638$ & 599 & 313-1049 & & & $271 / 733(37.0)$ & \\
\hline$>2 \mathrm{~h}$ & $743 \pm 589$ & 697 & $390-1003$ & & & $103 / 299(34.4)$ & \\
\hline Weekend days & & & & $5.147 * *$ & & & 2.353 \\
\hline$\leqslant 2 \mathrm{~h}$ & $832 \pm 721$ & 701 & 388-1309 & & & $127 / 382(33.2)$ & \\
\hline$>2 \mathrm{~h}$ & $607 \pm 598$ & 391 & $187-883$ & & & $247 / 650(38.0)$ & \\
\hline
\end{tabular}

Notes: ${ }^{* *} p<0.01$; MVPA: moderate and vigorous physical activity; IPA: insufficient physical activity; BMI: body mass index; SES: socioeconomic status.

\subsection{Influential Factors of Insufficient Physical Activity}

Multivariate analyses found that boys (OR (odds ratio) $=0.7,95 \% \mathrm{CI}$ (confidence interval): $0.5-0.9)$, adolescents with underweight status (OR $=0.5,95 \%$ CI: $0.3-0.7)$, and those with perceived high family support for physical activity (OR $=0.7,95 \% \mathrm{CI}$ : $0.6-0.9)$ were less likely to report IPA (Table 3). In contrast, those who were obese (OR $=2.2,95 \%$ CI: $1.5-2.9)$ and of high SES (OR = 2.4, 95\% CI: 1.3-4.8) were more likely to report IPA.

Table 3. Influential factors of insufficient physical activity among junior high school students $(n=1032)$.

\begin{tabular}{|c|c|c|c|c|c|c|}
\hline Variables & Crude OR & $95 \% \mathrm{CI}$ & $p$ & Adjusted OR & $95 \% \mathrm{CI}$ & $p$ \\
\hline \multicolumn{7}{|l|}{ Age } \\
\hline $12-13$ (ref) & 1 & & & & & \\
\hline 14-15 & 1.2 & $0.7-2.4$ & 0.57 & & & \\
\hline \multicolumn{7}{|l|}{ Gender } \\
\hline Girls (ref) & 1 & & & 1 & & \\
\hline Boys & 0.6 & $0.4-0.7$ & 0.000 & 0.7 & $0.5-0.9$ & 0.01 \\
\hline \multicolumn{7}{|l|}{ BMI status } \\
\hline Average weight (ref) & 1 & & & 1 & & \\
\hline Underweight & 0.4 & $0.3-0.6$ & 0.000 & 0.5 & $0.3-0.7$ & 0.004 \\
\hline Overweight & 0.9 & $0.6-1.4$ & 0.66 & 1.0 & $0.7-1.7$ & 0.72 \\
\hline Obese & 2.0 & $1.4-2.7$ & 0.000 & 2.2 & $1.5-2.9$ & 0.000 \\
\hline \multicolumn{7}{|l|}{ Socioeconomic status } \\
\hline Low (ref) & 1 & & & 1 & & \\
\hline Medium & 0.8 & $0.6-1.0$ & 0.04 & 0.8 & $0.6-1.0$ & 0.25 \\
\hline High & 1.9 & $1.2-3.0$ & 0.01 & 2.4 & $1.3-4.8$ & 0.007 \\
\hline \multicolumn{7}{|l|}{ Family support level } \\
\hline Low (ref) & 1 & & & 1 & & \\
\hline High & 0.5 & $0.4-0.7$ & 0.000 & 0.7 & $0.6-0.9$ & 0.004 \\
\hline
\end{tabular}




\section{Discussion}

Our findings suggest that Chinese youth, much like youth in Western countries, suffer from IPA [3,4]. Similar to what has been found in Western countries, girls, obese adolescents, and those with low family support for physical activity were more likely to report IPA [5,6]. High SES was positively associated with IPA among junior high school students, which has not been shown consistently in previous studies [20,27].

The present study is largely consistent with previous studies in China showing a high prevalence of IPA, although our data suggest a slight improvement over time $[5,6]$. In order to promote physical activity among students, the Chinese government had issued a series of guidelines since 2007 [28], requiring primary and middle schools to provide at least two physical education sessions per week, including an additional $60 \mathrm{~min}$ of daily exercise after class. Although still unclear, these policies may help to explain why physical activity appears to have increased among Chinese youth in the past few years.

Family support may influence physical activity $[17,29,30]$. Vander et al. suggested that increased parental encouragement was positively associated with boys' and girls' physical activity on school days and girls' physical activity on weekends [30]. A systemic review of studies published between 1998 and 2013 indicated the important aspects of parenting in children's physical activity, including parent encouragement and support [29]. This conclusion seems reasonable considering that parents often provide their children transportation, equipment and time for doing physical activity [17]. Parents' participation in the activity also appears to increase physical activity in children [31,32]. Thus, physical activity interventions with adolescents should consider increasing family support level, while increased family support for physical activity is helpful to motivate MVPA and reduce the risk of IPA.

Our study found that boys engaged in more MVPA than girls, a finding consistent with a recent study in Beijing, China [6]. Higher physical activity in boys has also observed in Kenya [10], Canada [33], and Germany [34]. Explanations for this trend include societal roles that emphasize sports and outdoor activities for boys $[5,35]$. Boys may also biologically be more inclined to engage in moderate to vigorous physical activity [11]. The results of the present study also suggest that boys have higher levels of family support than girls, which may also contribute to the gender disparity in physical activity. This finding further highlights the importance of increasing family support for physical activity.

We observed an inverse association between BMI and physical activity, a finding consistent with those of other study [23,36]. For example, studies by both Biernat [19] and Borges [36] reported that having a higher BMI significantly reduced the probability of meeting recommended MVPA. However, in most studies it is not clear whether IPA resulted in obesity and overweight, or whether obesity contributed to IPA. One might expect that IPA may result in a vicious cycle, whereby increasing BMI promotes further sedentary behavior.

Our study suggests that high SES is inversely correlated with physical activity, which is not consistent with previous studies in Western countries [23,27]. Lopes et al. reported that high income increased the risk of IPA [37]. On the contrary, it was found that the lower income neighborhoods had lower physical activity compared with middle and higher income neighborhoods [20]. In addition, Graham suggested that a low SES was associated with lower physical activity [38]. Although it is not currently clear, perhaps our finding of an inverse association between physical activity and SES may be due to the fact that children living in a family with no cars need to walk more and therefore have a higher level of physical activity [26].

Studies of the correlation between age and physical activity have shown mixed results. One study showed that students aged 17 to 19 had a higher risk of IPA than those aged 13 to 16 years [15]. Another study stated that a significant age-gradient in adults' physical activity could be seen in China, Ghana, Mexico, India, Russia and South Africa, where the prevalence IPA also consistently increased with increasing age [39]. Bastos reported the prevalence of IPA increased with age in girls but not in 
boys [31]. In contrast, no significant association between age and the level of physical activity was found in the present study. The sample age ranged from 12 years to 15 years old, so this null finding may be due to the relative narrow age range in our sample.

Several limitations of our study must be considered. We collected data of physical activity in weekly increments. Therefore, daily patterns in physical activity were not considered. Also, data were collected in spring and summer, during which higher physical activity is to be expected [40]. Further, the present study was limited by the self-reported exposure to physical activity, which may be less reliable than standardized accelerometer measurements. However, the PAQMSS was shown to be a reliable and reasonably valid instrument through pretest via ActiGraph GT3X triaxial accelerometers in a small sample $(n=50)$. Lastly, the present study was conducted in only one city, and therefore may not be generalizable to the entire country. However, $\mathrm{X}^{\prime}$ an is considered a typical city in Northwest China, therefore, may be representative of a considerable number of communities in China.

\section{Conclusions}

In summary, this study estimated the prevalence of IPA among junior high school students in Xi'an City, China. IPA was positively associated with female gender, obesity, high family income, and low family support level. These findings may be useful in the implementation of targeted interventions to prevent the many known health consequences of a sedentary lifestyle.

Acknowledgments: This work was financially supported by a grant (Grant NO. 81101333) from National Natural Science Foundation of China. Specially thanks to the teachers and administrators in those nine schools in Xi'an, Shaanxi Province. We also gratefully acknowledge the adolescents who participated in this study.

Author Contributions: Xiaoqin Wang and Paul D. Terry were responsible for the study design. Wei Gu developed the questionnaire. Mei Ma and Fu Deng were responsible for data collection. Li Cheng and Bin Zhang conducted the data analyses. Zhaozhao Hui drafted the manuscript. All authors contributed to the revisions of ultimate drafts of the manuscript and approved the version submitted for publication.

Conflicts of Interest: The authors declare no conflict of interest.

\section{Abbreviations}

The following abbreviations are used in this manuscript:

$\begin{array}{ll}\text { MVPA } & \text { Moderate and Vigorous Physical Activity } \\ \text { IPA } & \text { Insufficient Physical Activity } \\ \text { OR } & \text { Odds Ratio } \\ \text { CI } & \text { Confidence Interval } \\ \text { SES } & \text { Socioeconomic Status } \\ \text { WHO } & \text { World Health Organization } \\ \text { PAQMSS } & \text { Physical Activity Questionnaire for Middle School Students } \\ \text { BMI } & \text { Body Mass Index } \\ \mathrm{kg} / \mathrm{m}^{2} & \text { Kilogram per Square Meter } \\ \text { RMB } & \text { Renminbi } \\ \text { SPSS } & \text { Statistical Product and Service Solutions }\end{array}$

\section{References}

1. World Health Organization. WHO guidelines approved by the guidelines review committee. In Global Recommendations on Physical Activity for Health; World Health Organization: Geneva, Switzerland, 2010.

2. De Moraes, A.C.; Guerra, P.H.; Menezes, P.R. The worldwide prevalence of insufficient physical activity in adolescents; a systematic review. Nutr. Hosp. 2013, 28, 575-584. [PubMed]

3. De Cocker, K.; Ottevaere, C.; Sjostrom, M.; Moreno, L.A.; Warnberg, J.; Valtuena, J.; Manios, Y.; Dietrich, S.; Mauro, B.; Artero, E.G.; et al. Self-reported physical activity in European adolescents: results from the HELENA (Healthy Lifestyle in Europe by Nutrition in Adolescence study. Public Health Nutr. 2011, 14, 246-254. [CrossRef] [PubMed] 
4. Decelis, A.; Jago, R.; Fox, K.R. Physical activity, screen time and obesity status in a nationally representative sample of Maltese youth with international comparisons. BMC Public Health 2014, 14, 664. [CrossRef] [PubMed]

5. Teng, Y.K.; Huang, J.L.; Yeh, K.W.; Fu, L.S.; Lin, C.H.; Ma, W.F.; Lee, S.D.; Chiang, L.C. Influential factors of insufficient physical activity among adolescents with asthma in Taiwan. PLoS ONE 2014, 9, e116417. [CrossRef] [PubMed]

6. Duan, J.; Hu, H.; Wang, G.; Arao, T. Study on current levels of physical activity and sedentary behavior among middle school students in Beijing, China. PLoS ONE 2015, 10, e0133544. [CrossRef] [PubMed]

7. Rossen, J.; Yngve, A.; Hagstromer, M.; Brismar, K.; Ainsworth, B.E.; Iskull, C.; Moller, P.; Johansson, U.B. Physical activity promotion in the primary care setting in pre- and type 2 diabetes-The Sophia step study, an RCT. BMC Public Health 2015, 15, 647. [CrossRef] [PubMed]

8. Aguilar Cordero, M.J.; Ortegon Pinero, A.; Mur Vilar, N.; Sanchez Garcia, J.C.; Garcia Verazaluce, J.J.; Garcia Garcia, I.; Sanchez Lopez, A.M. Physical activity programmes to reduce overweight and obesity in children and adolescents; a systematic review. Nutr. Hosp. 2014, 30, 727-740. [PubMed]

9. Hallal, P.C.; Victora, C.G.; Azevedo, M.R.; Wells, J.C. Adolescent physical activity and health: A systematic review. Sports Med. 2006, 36, 1019-1030. [CrossRef] [PubMed]

10. Muthuri, S.K.; Wachira, L.J.; Onywera, V.O.; Tremblay, M.S. Correlates of objectively measured overweight/obesity and physical activity in Kenyan school children: Results from ISCOLE-Kenya. BMC Public Health 2014, 14, 436. [CrossRef] [PubMed]

11. Wu, X.; Tao, S.; Zhang, Y.; Zhang, S.; Tao, F. Low physical activity and high screen time can increase the risks of mental health problems and poor sleep quality among Chinese college students. PLoS ONE 2015, 10, e0119607. [CrossRef] [PubMed]

12. Guilherme, F.R.; Molena-Fernandes, C.A.; Guilherme, V.R.; Favero, M.T.; dos Reis, E.J.; Rinaldi, W. Physical inactivity and anthropometric measures in school children from Paranavaí, Paraná, Brazil. Rev. Paul. Pediatr. 2015, 33, 50-55. [CrossRef] [PubMed]

13. Zhang, Y.; Zhang, D.; Jiang, Y.; Sun, W.; Wang, Y.; Chen, W.; Li, S.; Shi, L.; Shen, X.; Zhang, J.; et al. Association between physical activity and teacher-reported academic performance among fifth-graders in Shanghai: A quantile regression. PLoS ONE 2015, 10, e0115483. [CrossRef] [PubMed]

14. Gomes da Silva, S.; Arida, R.M. Physical activity and brain development. Expert Rev. Neurother. 2015, 15, 1041-1051. [CrossRef] [PubMed]

15. Ceschini, F.L.; Andrade, D.R.; Oliveira, L.C.; Araujo Junior, J.F.; Matsudo, V.K. Prevalence of physical inactivity and associated factors among high school students from state's public schools. J. Pediatr. 2009, 85, 301-306. [CrossRef]

16. Dumith, S.C.; Gigante, D.P.; Domingues, M.R.; Kohl, H.W., 3rd. Physical activity change during adolescence: A systematic review and a pooled analysis. Int. J. Eidemiol. 2011, 40, 685-698. [CrossRef] [PubMed]

17. Tate, E.B.; Shah, A.; Jones, M.; Pentz, M.A.; Liao, Y.; Dunton, G. Toward a better understanding of the link between parent and child physical activity levels: The moderating role of parental encouragement. J. Phys. Act. Health 2015, 12, 1238-1244. [CrossRef] [PubMed]

18. Cardon, G.; Philippaerts, R.; Lefevre, J.; Matton, L.; Wijndaele, K.; Balduck, A.L.; De Bourdeaudhuij, I. Physical activity levels in 10- to 11-year-olds: clustering of psychosocial correlates. Public Health Nutr. 2005, 8, 896-903. [CrossRef] [PubMed]

19. Biernat, E.; Tomaszewski, P. Association of socio-economic and demographic factors with physical activity of males and females aged 20-69 years. Ann. Agric. Env. Med. 2015, 22, 118-123. [CrossRef] [PubMed]

20. Lord, S.; Manlhiot, C.; Tyrrell, P.N.; Dobbin, S.; Gibson, D.; Chahal, N.; Stearne, K.; Fisher, A.; McCrindle, B.W. Lower socioeconomic status, adiposity and negative health behaviours in youth: A cross-sectional observational study. BMJ Open 2015, 5, e008291. [CrossRef] [PubMed]

21. Siceloff, E.R.; Wilson, D.K.; Van, H.L. A longitudinal study of the effects of instrumental and emotional social support on physical activity in underserved adolescents in the ACT trial. Ann. Behav. Med. 2014, 48, 71-79. [CrossRef] [PubMed]

22. Beets, M.W.; Cardinal, B.J.; Alderman, B.L. Parental social support and the physical activity-related behaviors of youth: A review. Health Educ. Behav. 2010, 37, 621-644. [CrossRef] [PubMed] 
23. De Onis, M.; Onyango, A.W.; Borghi, E.; Siyam, A.; Nishida, C.; Siekmann, J. Development of a WHO growth reference for school-aged children and adolescents. Bull. World Health Organ. 2007, 85, 660-667. [CrossRef] [PubMed]

24. Lee, P.H. The Stages of Exercise, Physical Activity and Their Determinants: A Study of the Middle Aged from the Chungshan District in Taipei. Ph.D. Thesis, National Taiwan Normal University, Taibei, Taiwan, 2000.

25. Fogelholm, M.; Malmberg, J.; Suni, J.; Santtila, M.; Kyrolainen, H.; Mantysaari, M.; Oja, P. International physical activity questionnaire: Validity against fitness. Med. Sci. Sports Exer. 2006, 38, 753-760. [CrossRef] [PubMed]

26. Pouliou, T.; Sera, F.; Griffiths, L.; Joshi, H.; Geraci, M.; Cortina-Borja, M.; Law, C. Environmental influences on children's physical activity. J. Epidemiol. Community Health 2015, 69, 77-85. [CrossRef] [PubMed]

27. Drenowatz, C.; Eisenmann, J.C.; Pfeiffer, K.A.; Welk, G.; Heelan, K.; Gentile, D.; Walsh, D. Influence of socio-economic status on habitual physical activity and sedentary behavior in 8- to 11-year old children. BMC Public Health 2010, 10, 214. [CrossRef] [PubMed]

28. Ding, H.; Li, Y.; Wu, X. A review of scholarly and research work in physical education in China during the first decade of the 21st century. Quest 2014, 66, 117-133. [CrossRef]

29. Xu, H.; Wen, L.M. Associations of parental influences with physical activity and screen time among young children: A systematic review. J. Obes. 2015, 2015, 546925. [CrossRef] [PubMed]

30. Vander Ploeg, K.A.; Kuhle, S.; Maximova, K.; McGavock, J.; Wu, B.; Veugelers, P.J. The importance of parental beliefs and support for pedometer-measured physical activity on school days and weekend days among Canadian children. BMC Public Health 2013, 13, 1132. [CrossRef] [PubMed]

31. Bastos, J.P.; Araujo, C.L.; Hallal, P.C. Prevalence of insufficient physical activity and associated factors in Brazilian adolescents. J. Phys. Act. Health 2008, 5, 777-794. [PubMed]

32. Kuo, J.; Voorhees, C.C.; Haythornthwaite, J.A.; Young, D.R. Associations between family support, family intimacy, and neighborhood violence and physical activity in urban adolescent girls. Am. J. Public Health 2007, 97, 101-103. [CrossRef] [PubMed]

33. Colley, R.C.; Garriguet, D.; Janssen, I.; Craig, C.L.; Clarke, J.; Tremblay, M.S. Physical activity of Canadian children and youth: Accelerometer results from the 2007 to 2009 Canadian health measures survey. Health Rep. 2011, 22, 15-23. [PubMed]

34. Czerwinski, F.; Finne, E.; Kolip, P.; Bucksch, J. Individual and school level correlates of moderate to vigorous physical activity among school-children in Germany-A multi-level analysis. BMC Public Health 2015, 15, 393. [CrossRef] [PubMed]

35. Hong, Z. An investigation of the gender stereotyped thinking of Taiwanese secondary school boys and girls. Sex Roles 2003, 48, 495-504. [CrossRef]

36. Borges, A.; Gomes, T.N.; Santos, D.; Pereira, S.; dos Santos, F.K.; Chaves, R.; Katzmarzyk, P.T.; Maia, J. A count model to study the correlates of $60 \mathrm{~min}$ of daily physical activity in Portuguese children. Int. J. Environ. Res. Public Health 2015, 12, 2557-2573. [CrossRef] [PubMed]

37. Lopes, J.A.; Longo, G.Z.; Peres, K.G.; Boing, A.F.; de Arruda, M.P. Factors associated with insufficient physical activity: A population-based study in southern Brazil. Rev. Bras. Epidemiol. 2010, 13, 689-698. [CrossRef] [PubMed]

38. Graham, D.J.; Bauer, K.W.; Friend, S.; Barr-Anderson, D.J.; Nuemark-Sztainer, D. Personal, behavioral, and socio-environmental correlates of physical activity among adolescent girls: Cross-sectional and longitudinal associations. J. Phys. Act. Health 2014, 11, 51-61. [CrossRef] [PubMed]

39. Wu, F.; Guo, Y.; Chatterji, S.; Zheng, Y.; Naidoo, N.; Jiang, Y.; Biritwum, R.; Yawson, A.; Minicuci, N.; Salinas-Rodriguez, A.; et al. Common risk factors for chronic non-communicable diseases among older adults in China, Ghana, Mexico, India, Russia and South Africa: The study on global AGEing and adult health (SAGE) wave 1. BMC Public Health 2015, 15, 88. [CrossRef] [PubMed]

40. Rich, C.; Griffiths, L.J.; Dezateux, C. Seasonal variation in accelerometer-determined sedentary behaviour and physical activity in children: A review. Int. J. Behav. Nutr. Phys. Act. 2012, 9, 49. [CrossRef] [PubMed]

(C) 2016 by the authors; licensee MDPI, Basel, Switzerland. This article is an open access article distributed under the terms and conditions of the Creative Commons by Attribution (CC-BY) license (http:/ / creativecommons.org/licenses/by/4.0/). 